\title{
Cardiothoracic
}

Transplantation

\section{Should lung transplantation be performed using donation after cardiac death? The United States experience}

David P. Mason, MD, ${ }^{a}$ Lucy Thuita, MS, ${ }^{b}$ Joan M. Alster, MS, ${ }^{\text {b }}$ Sudish C. Murthy, MD, PhD, ${ }^{\text {a }}$ Marie M. Budev, DO, ${ }^{c}$ Atul C. Mehta, $\mathrm{MD}^{\mathrm{c}}{ }^{\mathrm{a}}$ Gösta B. Pettersson, MD, $\mathrm{PhD}^{\mathrm{a}}$ and Eugene H. Blackstone, MD ${ }^{\mathrm{a}, \mathrm{b}}$

From the Departments of Thoracic and Cardiovascular Surgery, ${ }^{\text {a }}$ Quantitative Health Sciences, ${ }^{\mathrm{b}}$ and Pulmonary, Allergy, and Critical Care Medicine, ${ }^{\mathrm{c}}$ Cleveland Clinic, Cleveland, Ohio.

This study was supported in part by the Peter and Elizabeth C. Tower and Family Endowed Chair in Cardiothoracic Research, James and Sharon Kennedy, the Slosburg Family Charitable Trust, Stephen and Saundra Spencer (G.B.P.), and the Kenneth Gee and Paula Shaw, PhD, Chair in Heart Research (E.H.B.).

This article was presented at the 88 th Annual Meeting of the American Association for Thoracic Surgery, San Diego, California, May 10-14, 2008.

Received for publication Feb 4, 2008; accepted for publication April 20, 2008.

Address for reprints: David P. Mason, MD, Cleveland Clinic, Department of Thoracic and Cardiovascular Surgery, 9500 Euclid Avenue/Desk F24, Cleveland, OH 44195 (E-mail: masond2@ccf.org).

J Thorac Cardiovasc Surg 2008;136:1061-6 0022-5223/\$34.00

Copyright $\odot 2008$ by The American Association for Thoracic Surgery

doi:10.1016/j.jtcvs.2008.04.023
Objective: We compared 1) survival after lung transplantation of recipients of donation after cardiac death (DCD) versus brain death donor organs in the United States and 2) recipient characteristics.

Methods: Data were obtained from the United Network for Organ Sharing for lung transplantation from October 1987 to May 2007. Follow-up after DCD lung transplantation extended to 8.6 years, median 1 year. Differences among recipients of DCD versus brain death donor organs were expressed as a propensity score for use in comparing risk-adjusted survival.

Results: A total of 14,939 transplants were performed, 36 with DCD organs ( 9 single, 27 double). Among the 36 patients, 3 have died after 1 day, 11 days, and 1.5 years. Unadjusted survival at $1,6,12$, and 24 months was $94 \%, 94 \%, 94 \%$, and $87 \%$, respectively, for DCD donors versus $92 \%, 84 \%, 78 \%$, and $69 \%$, respectively, for brain death donors $(P=.04)$. DCD recipients were more likely to undergo double lung transplantation and have diabetes, lower forced 1-second expiratory volume, and longer cold ischemic times. Once these were accounted for and propensity adjusted, survival was still better for DCD recipients, although the $P$ value equals .06 .

Conclusion: Concern about organ quality and ischemia-reperfusion injury has limited the application of lung DCD. However, DCD as practiced in the United States results in survival at least equivalent to that after brain death donation. It also demonstrates selection bias, particularly in performing double lung transplantation, making generalization regarding survival difficult. Nevertheless, the data support the expanded use of DCD.

$\mathrm{H}$ ardy and colleagues ${ }^{1}$ performed the first human lung transplant in 1963, using an organ from a donor who had died of congestive heart failure. This technique of organ retrieval would now be considered DCD. The organ was harvested after pronouncement of death in the emergency department, where the donor had undergone closed cardiac compressions until consent was obtained from the family.

Since then, careful definitions of brain death have been established, and almost all solid-organ use has been restricted to donors who meet brain death criteria before cessation of cardiac activity. ${ }^{2-4}$ However, this practice excludes patients who have dismal prognoses but whose condition does not fulfill the strict definitions of brain death. This group of patients holds the potential to substantially increase the donor pool. ${ }^{5}$ 


\section{Abbreviations and Acronyms \\ DCD = donation after cardiac death \\ LAS = lung allocation score \\ UNOS = United Network for Organ Sharing}

As the waiting list for transplantation continues to grow, solid-organ donation using DCD has recently begun to expand, particularly for renal and hepatic transplantation. ${ }^{6,7}$ Outcomes for recipients of these DCD organs seem promising. However, the lung transplant community has been slow to adopt DCD, primarily because of the concern that increased warm ischemia might produce organ injury and graft dysfunction. This has resulted in few publications describing the clinical results of lung transplantation using $\mathrm{DCD},{ }^{8-12}$ and no single center has a large experience. For this reason, we queried the United Network for Organ Sharing (UNOS) registry to analyze the impact of DCD as performed in the United States on survival after lung transplantation.

\section{Patients and Methods \\ Patients}

From October 1987 to April 2007, of 14,939 lung transplant recipients with follow-up data, 36 underwent transplantation using DCD at 11 centers. Recipient and donor data and duration of follow-up for survival were obtained from the UNOS database. Mean age of the DCD and non-DCD groups at transplant was similar at $48 \pm 14$ years. Two patients in the DCD group and 733 patients in the non-DCD group were children ( $<18$ years). Mean donor age was $32 \pm 14$ years for the DCD group and $30 \pm 14$ years for the non-DCD group (Tables 1 and 2).

\section{Follow-up}

Median follow-up was 1.0 years for DCD survivors and 2.9 years for non-DCD survivors. Ten percent of all patients were followed more than 9 years; $10 \%$ of DCD patients were followed more than 3.9 years.

\section{Data Analysis}

Propensity score. Because DCD recipients differed from nonDCD recipients in a number of characteristics, a propensity score was developed using multivariable logistic regression to permit at least limited risk adjustment of the survival comparison. ${ }^{13}$ Selection of variables for the propensity model was based on univariable statistical significance, relevance in lung transplantation, and availability of data (Table 3). Variables included recipient age, body mass index, history of diabetes, chronic obstructive pulmonary disease/ emphysema diagnosis, oxygen requirement at rest, percent of predicted forced expiratory volume in 1 second, double lung transplantation, organ ischemic time, and donor age. Sporadic missing values were replaced by simple means imputation.

Survival after transplant. Unadjusted nonparametric survival estimates were obtained using the Kaplan-Meier method. For adjusted patient survival, a Cox proportional hazards model was constructed with 2 variables: DCD donor and the propensity score.
TABLE 1. Population characteristics (categoric variables)

\begin{tabular}{|c|c|c|c|}
\hline Characteristic & $\begin{array}{c}\text { DCD } \\
\frac{(n=36)}{\text { No. }(\%)}\end{array}$ & $\begin{array}{c}\begin{array}{c}\text { Non-DCD } \\
(\mathrm{n}=14,903)\end{array} \\
\text { No. }(\%)\end{array}$ & $P$ \\
\hline \multicolumn{4}{|l|}{ Recipient } \\
\hline \multicolumn{4}{|l|}{ Demographic } \\
\hline Female & $19(53)$ & $7371(49)$ & .7 \\
\hline White & $34(94)$ & $13,196(89)$ & .3 \\
\hline African-American & $2(5.6)$ & $973(6.5)$ & .8 \\
\hline \multicolumn{4}{|l|}{ Diagnosis } \\
\hline COPD/emphysema & $14(39)$ & 5554 (37) & .8 \\
\hline $\begin{array}{l}\text { Idiopathic pulmonary } \\
\text { fibrosis }\end{array}$ & $1(2.8)$ & $2786(19)$ & .01 \\
\hline Cystic fibrosis & $9(25)$ & $2458(16)$ & .2 \\
\hline$\alpha-1$ antitrypsin deficiency & $3(8.3)$ & $1162(7.8)$ & .9 \\
\hline Sarcoidosis & $2(5.6)$ & $408(2.7)$ & .3 \\
\hline Bronchiectasis & $1(2.8)$ & $300(2.0)$ & .7 \\
\hline Lymphangioleiomyomatosis & $1(2.8)$ & $121(0.81)$ & .2 \\
\hline Crest syndrome & $1(2.8)$ & $4(0.027)$ & $<.0001$ \\
\hline $\begin{array}{l}\text { Retransplant for graft } \\
\text { failure }\end{array}$ & $3(8.3)$ & $38(0.25)$ & $<.0001$ \\
\hline \multicolumn{4}{|l|}{ Comorbidities } \\
\hline History of smoking & $12(67)$ & $1568(61)$ & .6 \\
\hline Diabetes & $8(23)$ & $1193(9.8)$ & .01 \\
\hline \multicolumn{4}{|l|}{ Surgical } \\
\hline Double lung transplant & $27(75)$ & $7263(49)$ & .002 \\
\hline \multicolumn{4}{|l|}{ Donor } \\
\hline \multicolumn{4}{|l|}{ Demographic } \\
\hline Female & $18(50)$ & $5612(38)$ & .1 \\
\hline White & $32(89)$ & $10,788(72)$ & .03 \\
\hline African-American & $2(5.6)$ & $2169(15)$ & .1 \\
\hline Other & $2(5.6)$ & $1946(13)$ & .2 \\
\hline \multicolumn{4}{|l|}{ Comorbidities } \\
\hline Smoking: $>20$ pack/y & $4(11)$ & $3151(25)$ & .06 \\
\hline Hypertension & $8(23)$ & $1801(14)$ & .2 \\
\hline Clinical infection & $10(29)$ & $2849(23)$ & .5 \\
\hline Serology anti-CMV & $15(44)$ & 8195 (57) & .1 \\
\hline
\end{tabular}

$C M V$, Cytomegalovirus; $C O P D$, chronic obstructive pulmonary disease; $D C D$, donation after cardiac death.

\section{Data Presentation}

Continuous variables are summarized by mean \pm standard deviation except for skewed variables, which are summarized by equivalent 15 th, 50th (median), and 85th percentiles. Categoric data are summarized by frequency and percentage. All analyses were performed using SAS statistical software (SAS v9.1; SAS, Inc, Cary, NC). Survival estimates and hazard ratios are accompanied by $68 \%$ confidence limits equivalent to \pm 1 standard error.

\section{Results}

\section{Survival}

Overall survival after lung transplantation at $1,3,6,12$, and 24 months was $94 \%, 94 \%, 94 \%, 94 \%$, and $87 \%$, respectively, for recipients receiving lungs from DCD donors, compared with $92 \%, 88 \%, 84 \%, 78 \%$, and $69 \%$, respectively, for brain 
TABLE 2. Population characteristics (continuous variables)

\begin{tabular}{|c|c|c|c|c|c|}
\hline \multirow[b]{2}{*}{ Characteristic } & \multicolumn{2}{|r|}{ DCD } & \multicolumn{2}{|c|}{ Non-DCD } & \multirow[b]{2}{*}{$\boldsymbol{P}$} \\
\hline & $\mathbf{n}^{\mathbf{a}}$ & $\begin{array}{l}\text { Mean } \pm \text { SD or } 15 \text { th, } \\
\text { 50th, } 85 \text { th percentiles }\end{array}$ & $\mathbf{n}^{\mathrm{a}}$ & $\begin{array}{c}\text { Mean } \pm \text { SD or 15th, } \\
\text { 50th, 85th percentiles }\end{array}$ & \\
\hline \multicolumn{6}{|l|}{ Recipient } \\
\hline \multicolumn{6}{|l|}{ Demographic } \\
\hline Age (y) & 36 & $48 \pm 14$ & 14,903 & $48 \pm 15$ & .9 \\
\hline Height $(\mathrm{cm})$ & 35 & $169 \pm 13$ & 14,401 & $168 \pm 13$ & .8 \\
\hline Weight (kg) & 35 & $67 \pm 20$ & 14,401 & $68 \pm 18$ & 6 \\
\hline $\mathrm{BMI}\left(\mathrm{kg} / \mathrm{m}^{2}\right)$ & 35 & $23 \pm 4.7$ & 14,401 & $24 \pm 4.9$ & .5 \\
\hline \multicolumn{6}{|l|}{ Pulmonary function } \\
\hline $\mathrm{O}_{2}$ at rest & 32 & $2.6 \pm 2.2$ & 11,270 & $2.7 \pm 2.3$ & .3 \\
\hline $\mathrm{PCO}_{2}$ & 31 & $49 \pm 11$ & 8905 & $46 \pm 12$ & .06 \\
\hline FEV1 ( $\%$ of predicted) & 32 & $25 \pm 11$ & 12,512 & $34 \pm 21$ & .09 \\
\hline FVC ( $\%$ of predicted) & 32 & $49 \pm 14$ & 12,423 & $50 \pm 18$ & 1 \\
\hline \multicolumn{6}{|l|}{ Hemodynamics } \\
\hline $\begin{array}{l}\text { Cardiac output } \\
\text { PPA }\end{array}$ & 21 & $5.8 \pm 1.6$ & 8199 & $5.3 \pm 1.5$ & .07 \\
\hline Systolic & 27 & $40 \pm 16$ & 9353 & $42 \pm 19$ & .3 \\
\hline Diastolic & 27 & $21 \pm 10$ & 9218 & $19.5 \pm 10$ & .7 \\
\hline Mean & 26 & $28 \pm 13$ & 8706 & $28 \pm 13$ & .9 \\
\hline PpcW & 26 & $15 \pm 9.1$ & 8648 & $11 \pm 5.9$ & .02 \\
\hline \multicolumn{6}{|l|}{ Other } \\
\hline Creatinine $(\mathrm{mg} / \mathrm{dL})$ & 36 & $0.54 / 0.8 / 1.2$ & 12,776 & $0.6 / 0.8 / 1.1$ & .7 \\
\hline LAS & 21 & $32 \pm 8$ & 2468 & $40 \pm 12$ & .0001 \\
\hline \multicolumn{6}{|l|}{ Surgical } \\
\hline $\begin{array}{l}\text { Maximum lung } \\
\text { ischemic time (min) }\end{array}$ & 31 & $371 \pm 120$ & 13,223 & $275 \pm 110$ & $<.0001$ \\
\hline Hospital stay & 33 & $9 / 17 / 37$ & 8949 & $9 / 15 / 39$ & .7 \\
\hline \multicolumn{6}{|l|}{ Donor } \\
\hline \multicolumn{6}{|l|}{ Demographic } \\
\hline Age (y) & 36 & $32 \pm 14$ & 14,894 & $30 \pm 14$ & .5 \\
\hline Height $(\mathrm{cm})$ & 34 & $170 \pm 12$ & 13,071 & $171 \pm 14$ & .5 \\
\hline Weight (kg) & 34 & $74 \pm 20$ & 13,071 & $72 \pm 17$ & .6 \\
\hline BMI $\left(\mathrm{kg} / \mathrm{m}^{2}\right)$ & 34 & $25 \pm 5.6$ & 13,071 & $24 \pm 4.6$ & .5 \\
\hline \multicolumn{6}{|l|}{ Other } \\
\hline Creatinine $(\mathrm{mg} / \mathrm{dL})$ & 35 & $0.5 / 0.85 / 1.1$ & 12,555 & $0.6 / 0.9 / 1.4$ & .01 \\
\hline
\end{tabular}

$B M I$, body mass index; $D C D$, donation after cardiac death; $F E V 1$, forced expiratory volume in 1 second; $F V C$, forced vital capacity; $L A S$, Lung allocation score; $P P A$, pulmonary artery pressure; $P P C W$, pulmonary capillary wedge pressure; $S D$, standard deviation. ${ }^{\text {a Available data. }}$

death donors. DCD seemed to be associated with increased survival (unadjusted $P=.04$, Figure 1). After adjustment for the propensity score, the hazard ratio for DCD recipients compared with non-DCD recipients was 0.34 (confidence limits, $0.19-0.60 ; P=.06$ ). Non-DCD recipients had slightly better survival immediately after transplant, but after day 20 , survival favored the DCD group. There were 2 early deaths in the DCD group, at 1 and 11 days, and a later death at 1.5 years. Causes of death were sepsis and hepatic failure, respectively, for the early deaths, and respiratory failure for the later death.

\section{Retransplantation}

Three DCD recipients underwent subsequent retransplantation at 23 days, 3 months, and 8.5 years. Indications were pri- mary graft dysfunction (day 23) and bronchiolitis obliterans (3 months and 8.5 years). Actuarial freedom from retransplantation was 92\% (confidence limits, 85\% - 96\%) at 1 year. Approximately $3.2 \%$ of non-DCD recipients underwent retransplantation within 1 day to 16 years of the primary transplant.

\section{Discussion}

This study evaluated all DCD lung transplants performed in the United States from 1987 to 2007. Although few have been performed, survival was surprisingly good and similar to or better than that for brain death donor transplantation. There were some notable differences in donor, recipient, and transplant characteristics between the 2 groups that deserve mention, however. 
TABLE 3. Comparison of DCD and non-DCD factors used in propensity analyses

\begin{tabular}{lcl}
\hline Factor & Coefficient \pm SE & $P$ \\
\hline Recipient & & \\
Age & $0.03 \pm 0.02$ & .1 \\
BMI & $-0.01 \pm 0.04$ & .8 \\
Oxygen requirement & $-0.08 \pm 0.1$ & .5 \\
COPD/emphysema diagnosis & $0.0004 \pm 0.4$ & .9 \\
Diabetes & $1.08 \pm 0.4$ & .01 \\
FEV1 (\% of predicted) & $-0.03 \pm 0.01$ & .04 \\
Double lung transplant & $0.86 \pm 0.4$ & .05 \\
Ischemic time & $0.005 \pm 0.001$ & .0002 \\
Donor & & \\
Age & $0.007 \pm 0.01$ & .6 \\
\hline
\end{tabular}

$B M I$, Body mass index; $C O P D$, chronic obstructive pulmonary disease; $D C D$, donation after cardiac death; $F E V 1$, forced expiratory volume in 1 second; $S E$, standard error.

The first is increased use of double lung transplantation in the brain death donor group. This may reflect 1) the increased number of double lung transplants being performed over the study period, ${ }^{14}$ with DCD being used more recently, or 2) a perception that DCD organs are inferior and thus 2 lungs might be preferable to 1 lung under these circumstances. Some studies suggest that double lung transplant imparts a survival advantage over single lung transplant, and the increased use of double lung transplant may have led to improved survival in the DCD group in our study. ${ }^{15-17}$

The second difference is the lower lung allocation score (LAS) observed in the DCD group. In 2005, the LAS was adopted to optimize organ use. ${ }^{18}$ In this system, a higher LAS score reflects increased disease severity and "sickness" of a patient coupled with the likelihood of deriving a survival

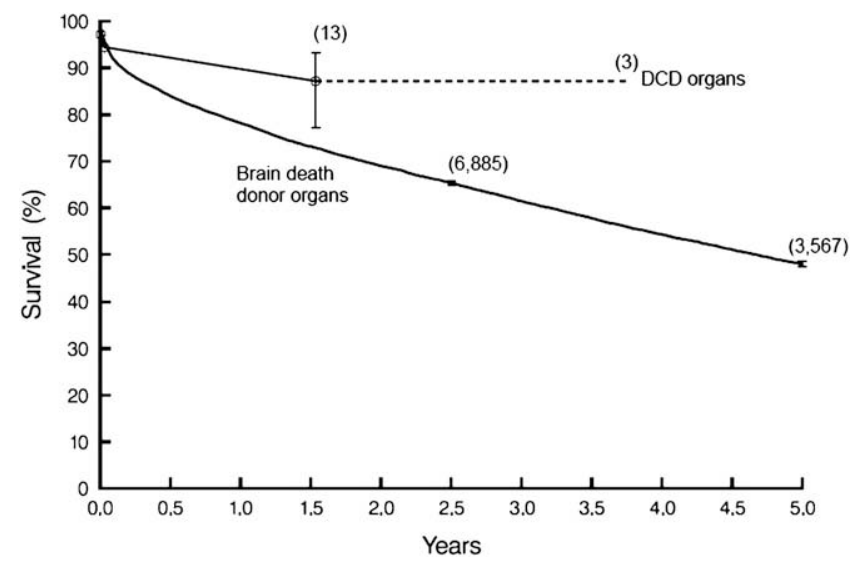

Figure 1. Overall survival stratified by mode of donation: cardiac death versus brain death. Symbols represent deaths, vertical bars represent $68 \%$ confidence limits, and numbers in parentheses represent patients remaining at risk. $D C D$, donation after cardiac death. benefit with transplantation. As a generalization, sicker patients get higher allocation scores. ${ }^{19}$ The observation that DCD recipients had lower LAS scores suggests that organs were used on "less sick" patients and may reflect a bias to use DCD organs in these patients because of perceived organ inferiority; such patients may be better able to tolerate graft dysfunction should it occur.

The third notable difference between the DCD and brain death groups is the considerably longer ischemic time of the DCD group. However, despite this known risk factor for graft dysfunction and mortality, survival was unaffected. $^{20,21}$ Finally, it is interesting to note that there was no significant difference between groups in hospital length of stay.

\section{Principal Findings}

Survival. Survival after lung transplantation using DCD donors in our study was excellent and, in fact, better than survival after brain death donation. Until now, published outcomes for DCD lung transplantation have been limited mainly to case reports. ${ }^{8-11}$ The largest case series of DCD donation previously reported (from Madrid, Spain) included 17 patients, and the results raised concern about the safety and efficacy of DCD. ${ }^{12}$ Early mortality was high at $17 \%$, and 1 -year survival was only $69 \%$. In our series, there were just 2 early deaths after transplantation, with 94\% survival at 3 months maintained to 1 year. One explanation for the differing results may be that the techniques of DCD organ procurement practiced in the Madrid series differed substantially from those practiced in the United States. In Madrid, cardiopulmonary resuscitation was attempted, followed by extracorporeal membrane oxygenation before organ recovery and transplantation. This technique is categorized as "uncontrolled" under the 1995 Maastricht classification system. ${ }^{22,23}$ Although the details of DCD are not specified in the UNOS registry, we believe that all patients in this study were controlled and in Maastricht category III, that is, donor treatment was withdrawn in the intensive care unit or operating room and organ retrieval commenced after a defined period of cardiac standstill.

The controlled technique has many theoretic advantages, such as preventing aspiration, minimizing warm ischemia time, and potentially reducing ischemia-reperfusion injury. Most programs and hospitals performing DCD specify a time frame in which death must occur after withdrawal of support or cancellation of procurement. Our own program specifies that death must occur within 1 hour, although some hospitals specify an even briefer period. In addition, controlled DCD allows time to identify and prepare an appropriate recipient for transplantation. All of these aspects likely contribute to improved survival.

This study demonstrates that DCD lung transplantation as practiced in the controlled setting can be performed with excellent survival. These results are particularly impressive 
given that so few DCD transplants have been performed and that no single institution has a large experience. One would expect some learning curve to be evident as the new technique is incorporated, but this was not demonstrated. However, generalization to uncontrolled methods of organ procurement cannot be made.

The unadjusted survival advantage for DCD raises the possibility that there may be some benefit to using DCD donors in lung transplantation. Brain death causes inflammatory mediator release and end-organ adhesion molecule and leukocyte accumulation, as well as increased organ immunogenicity in other solid-organ transplantation. ${ }^{24,25}$ Experimental evidence in lung transplantation suggests that DCD lungs might be less susceptible to ischemia-reperfusion injury and in fact be preferable to brain death donation organs. ${ }^{26,27}$ Further evaluation of clinical outcomes will be necessary before making this determination.

Retransplantation. The need for retransplantation is an important end point to examine when comparing outcomes after DCD versus brain death donation. Retransplantation represents one surrogate for severe graft dysfunction in the early postoperative period. If graft dysfunction is severe enough, retransplantation is an option for salvage. ${ }^{28}$ Only 1 patient in this study required early retransplantation for primary graft dysfunction. The need for retransplantation also reflects the immunologic influences of acute and chronic rejection. ${ }^{29}$ Two other patients required retransplantation at later time frames, and the prevalence was higher than observed after brain death donation; however, the numbers in the DCD group were small.

\section{Limitations}

Studies using registry data have the advantage of being able to compare survival using large numbers of patients; limitations include lack of adequate data collection to establish important secondary outcomes. This study has the same limitation, in that data were not available to adequately study the frequency and severity of primary graft dysfunction, rejection episodes, pulmonary function, postoperative complications, hospital readmissions, and quality of life, all important outcomes after lung transplantation. ${ }^{30}$ In addition, the number of DCD donors was small and follow-up was relatively short. However, we would expect that differences between recipients of brain death and DCD donation would be most evident in the early period after transplantation.

\section{Conclusions}

Our study demonstrates excellent survival and supports the expanded use of controlled DCD for lung transplantation in the United States.

\section{References}

1. Hardy JD, Webb WR, Dalton ML Jr, Walker GR Jr. Lung homotransplantation in man. JAMA. 1963;186:1065-74.
2. A definition of irreversible coma. Report of the Ad Hoc Committee of the Harvard Medical School to Examine the Definition of Brain Death. JAMA. 1968;205:337-40.

3. Guidelines for the determination of death. Report of the medical consultants on the diagnosis of death to the President's Commission for the Study of Ethical Problems in Medicine and Biomedical and Behavioral Research. JAMA. 1981;246:2184-6.

4. Curran WJ. The Uniform Anatomical Gift Act. N Engl J Med. 1969;280: 36-7.

5. Bernat JL, D'Alessandro AM, Port FK, Bleck TP, Heard SO, Medina J, et al. Report of a National Conference on Donation after cardiac death. Am J Transplant. 2006;6:281-91.

6. D'Alessandro AM, Fernandez LA, Chin LT, Shames BD, Turgeon NA, Scott DL, et al. Donation after cardiac death: the University of Wisconsin experience. Ann Transplant. 2004;9:68-71.

7. Locke JE, Segev DL, Warren DS, Dominici F, Simpkins CE, Montgomery RA. Outcomes of kidneys from donors after cardiac death: implications for allocation and preservation. Am J Transplant. 2007;7: 1797-807.

8. Loehe F, Mueller C, Annecke T, Siebel A, Bittmann I, Messmer KF, et al. Pulmonary graft function after long-term preservation of nonheart-beating donor lungs. Ann Thorac Surg. 2000;69:1556-62.

9. Oto T, Levvey B, McEgan R, Davies A, Pilcher D, Williams T, et al. A practical approach to clinical lung transplantation from a Maastricht Category III donor with cardiac death. J Heart Lung Transplant. 2007;26: 196-9.

10. Steen $\mathrm{S}$, Ingemansson $\mathrm{R}$, Budrikis $\mathrm{A}$, Bolys $\mathrm{R}$, Roscher $\mathrm{R}$, Sjoberg T. Successful transplantation of lungs topically cooled in the non-heart-beating donor for 6 hours. Ann Thorac Surg. 1997; 63:345-51.

11. Steen S, Liao Q, Wierup PN, Bolys R, Pierre L, Sjoberg T. Transplantation of lungs from non-heart-beating donors after functional assessment ex vivo. Ann Thorac Surg. 2003;76:244-52.

12. de Antonio DG, Marcos R, Laporta R, Mora G, Garcia-Gallo C, Gamez P, et al. Results of clinical lung transplant from uncontrolled non-heart-beating donors. J Heart Lung Transplant. 2007;26:529-34.

13. Blackstone EH. Comparing apples and oranges. J Thorac Cardiovasc Surg. 2002;123:8-15.

14. Orens JB, Shearon TH, Freudenburger RS, Conte JV, Bhorade SM, Ardehali A. Thoracic organ transplantation in the United States, 19952004. Am J Transplant. 2006;6:1188-97.

15. Meyer DM, Edwards LB, Torres F, Jessen ME, Novick RJ. Impact of recipient age and procedure type on survival after lung transplantation for pulmonary fibrosis. Ann Thorac Surg. 2005;79:950-8.

16. Cassivi SD, Meyers BF, Battafarano RJ, Guthrie TJ, Trulock EP, Lynch JP, et al. Thirteen-year experience in lung transplantation for emphysema. Ann Thorac Surg. 2002;74:1663-70.

17. Sundaresan RS, Shiraishi Y, Trulock EP, Manley J, Lynch J, Cooper JD, et al. Single or bilateral lung transplantation for emphysema? J Thorac Cardiovasc Surg. 1996;112:1485-95.

18. Egan TM, Murray S, Bustami RT, Shearon TH, McCullough KP, Edwards LB, et al. Development of the new lung allocation system in the United States. Am J Transplant. 2006;6:1212-27.

19. Davis SQ, Garrity ER Jr. Organ allocation in lung transplant. Chest. 2007;132:1646-51.

20. Thabut G, Mal H, Cerrina J, Dartevelle P, Dromer C, Velly JF, et al. Graft ischemic time and outcome of lung transplantation: a multicenter analysis. Am J Respir Crit Care Med. 2005;171:786-91.

21. Christie JD. Lung allograft ischemic time: crossing the threshold. Am J Respir Crit Care Med. 2005;171:673-4.

22. Van Raemdonck DE, Rega FR, Neyrinck AP, Jannis N, Verleden GM, Lerut TE. Non-heart-beating donors. Semin Thorac Cardiovasc Surg. 2004;16:309-21.

23. Kootstra G, Daemen JH. The non-heart-beating donor. Transplant Proc. 1996;28:16.

24. Nijboer WN, Schuurs TA, van der Hoeven JA, Leuvenink HG, van der Heide JJ, van Goor H, et al. Effects of brain death on stress and inflammatory response in the human donor kidney. Transplant Proc. 2005;37: 367-9.

25. Sanchez-Fructuoso A, Naranjo Garcia P, Calvo Romero N, Ridao N, Naranjo Gomez P, Conesa J, et al. Effect of the brain-death process on 
acute rejection in renal transplantation. Transplant Proc. 2007;39: 2214-6.

26. Neyrinck AP, Van De Wauwer C, Geudens N, Rega FR, Verleden GM, Wouters $\mathrm{P}$, et al. Comparative study of donor lung injury in heart-beating versus non-heart-beating donors. Eur J Cardiothorac Surg. 2006;30: 628-36.

27. Avlonitis VS, Wigfield CH, Golledge HD, Kirby JA, Dark JH. Early hemodynamic injury during donor brain death determines the severity of primary graft dysfunction after lung transplantation. Am J Transplant. 2007;7:83-90.
28. Magee JC, Barr ML, Basadonna GP, Johnson MR, Mahadevan S, McBride MA, et al. Repeat organ transplantation in the United States, 1996-2005. Am J Transplant. 2007;7:1424-33.

29. Martinu T, Howell DN, Davis RD, Steele MP, Palmer SM. Pathologic correlates of bronchiolitis obliterans syndrome in pulmonary retransplant recipients. Chest. 2006;129:1016-23.

30. Christie JD, Carby M, Bag R, Corris P, Hertz M, Weill D. Report of the ISHLT Working Group on Primary Lung Graft Dysfunction part II: definition. A consensus statement of the International Society for Heart and Lung Transplantation. J Heart Lung Transplant. 2005;24:1454-9. 